Published in final edited form as:

J Addict Nurs. 2012 October ; 23(3): 210-222. doi:10.1097/JAN.0b013e318271c123.

\title{
American Society for Pain Management Nursing Position Statement: Pain Management in Patients with Substance Use Disorders
}

\author{
June Oliver, MSN, CCNS, APN/CNS, \\ Swedish Covenant Hospital, Chicago, IL \\ Candace Coggins, MS, MA, RN-C, ACHPN, PMHNP-BC, \\ UCLA School of Nursing, Los Angeles, CA
}

Peggy Compton, RN, PhD, FAAN,

UCLA School of Nursing, Los Angeles, CA

Susan Hagan, MSN, ARNP-C, RN-BC,

James A Haley Veterans Administration Medical Center \& University of South Florida Tampa, FL

Deborah Matteliano, PhD, ANP, FNP, RN-BC,

Matteliano Pain Rehabilitation Center Buffalo, NY

Marsha Stanton, PhD, RN,

Horizon Pharma, Deefield, IL

Barbara St. Marie, PhD, ANP, GNP, RN-BC,

Fairview Ridges Hospital, Burnsville, MN

Stephen Strobbe, PhD, RN, NP, PMHCNS-BC, CARN-AP, and

University of Michigan Addiction Treatment Services

Helen N. Turner, DNP, RN-C, PCNS-BC, FAAN

Doernbecher Children's Hospital, Anesthesiology \& Peri-Operative Medicine, Oregon Health \& Science University, 3181 SW Sam Jackson Park Road, BTE-2, Portland, OR 97239-3098, Office: 503-418-5138, Fax: 503-494-5945

Helen N. Turner: turnerh@ohsu.edu

\section{Abstract}

The American Society for Pain Management Nursing (ASPMN) has updated its position statement on managing pain in patients with substance use disorders. This position statement is endorsed by the International Nurses Society on Addictions (IntNSA) and includes clinical practice

Correspondence to: Helen N. Turner, turnerh@ohsu. edu.

DECLARATION OF INTEREST:

This endeavor was underwritten by an unrestricted educational grant from King Pharmaceuticals.

Disclosure statement: Beginning August 1, 2012, I will begin in a Post Doctoral Fellowship that is funded by a federal grant, "Pain and Associated Symptoms: Nurse Research Training", T32 NR11147 at the University of Iowa, in Iowa City, IA. My appoint will begin August 1, 2012 and end on July 31, 2013. A second year of funding will be contingent upon my progress and achievement of goals during my first year and my likelihood of success in completing a grant proposal early in the second year. 
recommendations based on current evidence. It is the position of ASPMN and IntNSA that every patient with pain, including those with substance use disorders, has the right to be treated with dignity, respect, and high quality pain assessment and management. Failure to identify and treat the concurrent conditions of pain and substance use disorders will compromise the ability to treat either condition effectively. Barriers to caring for these patients include stigmatization, misconceptions, and limited access to providers skilled in these two categories of disorders. Topics addressed in this position statement include the scope of substance use and related disorders, conceptual models of addiction, ethical considerations, addiction risk stratification, and clinical recommendations.

\section{Key or Search Terms}

addiction; pain; opiate analgesics; position paper; substance use disorders

\section{Position Statement}

ASPMN and IntNSA hold the position that patients with substance use disorders and pain have the right to be treated with dignity, respect, and the same quality of pain assessment and management as all other patients. Safe and effective care of patients with substance use disorders includes maintaining a balance between the provision of pain relief, monitoring for appropriate use of prescribed medications and other substances, and recommendations for viable treatment alternatives. Nurses are well positioned and obligated to advocate for pain management across all treatment settings for patients at various points along a continuum of substance use.

\section{Background}

\section{Scope of Substance Use and Related Disorders}

Prevalence-Substance use and related disorders are common in our society. Illicit use of controlled substances is a leading category of medication misuse. In 2009, the number of Americans reporting current nonmedical use of prescription drugs exceeded the number using cocaine, heroin, hallucinogens, and inhalants combined (SAMHSA, 2010a). According to the Substance Abuse and Mental Health Services Administration (SAMHSA, 2011), in 2010, an estimated 22.6 million Americans (8.9\% of the population) aged 12 or older reported using an illicit substance in the previous month. Approximately 7 million of these individuals met diagnostic criteria for a drug use disorder, and an estimated 5.1 million persons reported they had used prescription pain relievers in a nonmedical or non-prescribed manner. Sixty-six percent of those individuals obtained these medications from a friend or relative, and nearly $80 \%$ of those friends or family members had each obtained their medications from a single prescriber. More than a third of those who had used these medications illicitly (1.9million persons) were classified as having abused or been dependent upon these substances (SAMHSA, 2011).

In the pediatric population, prescription opioids are the most commonly used drugs for nonmedical purposes. Too often children and youths mistakenly assume that prescription medications are safer than street drugs to relieve discomfort or to feel good. Nonmedical 
users can be divided into two distinct groups of self-treatment versus other reasons for use. In a study of adolescents by Boyd, McCabe, Cranford, and Young (2006), 69\% reported pain control for complaints such as headache or menstrual cramps as the primary reason for nonmedical opioid use. This may be more appropriately viewed as self-medicating or opioid misuse, which is associated with a lower risk for subsequent opioid abuse or dependence. A small minority $(11 \%)$ reported using prescription opioids solely to "get high". The National Center on Addiction and Substance Abuse at Columbia University (CASA, 2011) has called adolescent substance misuse-including alcohol, tobacco, and other drugs-the nation's number one health problem. The number of high school students who reported ever having misused opioids increased significantly between the beginning ( $8.3 \%$ of 9th graders) and end of high school (16.3\% of 12th graders), with nearly $13 \%$ having misused prescription opioids in their lifetime, and $3.4 \%$ currently misusing these substances (CASA, 2011; Frese \& Eiden, 2011). Diversion of prescription opioids is also common among pediatric nonmedical users. A full $75 \%$ of youths report borrowing medications from family or friends instead of seeing a healthcare provider.

Although sometimes overlooked, abuse/misuse of prescribed medications occurs in all ages, including middle aged and older adults. Additionally, as the population ages, experts predict that prescription drug abuse among the elderly will also rise significantly (Martin, 2008). In people aged 50 or older, an increase of up to $190 \%$ in nonmedical use of psychotherapeutic drugs is projected over two decades from 911,000 in 2001 up to 2.7 million in 2020 (Colliver, Compton, Gfroerer, \& Condon, 2006).

Over the past decade, there have been steadily rising rates of hospital admissions for the treatment of prescription opioid misuse. Visits to hospital emergency departments (ED) involving the nonmedical use of prescription analgesics rose $111 \%$, more than doubling the number of visits between 2004 and 2008. The top three medications mentioned in these visits were oxycodone, hydrocodone, and methadone products (SAMHSA, 2010b). Additionally, unintentional deaths related to opioids have reached epidemic proportions (Center for Disease Control and Prevention, 2010; Morbidity and Mortality Weekly Report, 2011). The risk of death is magnified when opioids are taken in combination with alcohol, sedatives, hypnotics, and anxiolytics.

Financial impact-The total cost of substance use to federal, state, and local governments is estimated to be a staggering $\$ 467.7$ billion per year (CASA, 2011). The National Prescription Drug Threat Assessment survey found controlled prescription diversion (CPD) occurs most often through doctor-shopping, prescription fraud, and theft (National Drug Intelligence Center [NDIC], 2010). The estimated cost of controlled prescription diversion is $\$ 72.5$ billion a year to public and private medical insurers, and this cost is passed on to consumers through higher health insurance premiums. In an effort to address some of these problems, prescription monitoring programs (PMPs) have been established in the majority of states, although no such national system currently exists. PMPs have been shown to reduce the number of prescriptions illicitly obtained through doctor-shopping (NDIC, 2010).

Implications for healthcare-In examining the intersection of persistent pain and addiction, problematic drug-taking behaviors have been identified in up to $40 \%$ of all pain 
patients; much fewer appear to actually have a substance use disorder. An estimated $20 \%$ of those individuals demonstrated behaviors suggestive of substance abuse, while only 2-5\% demonstrated behaviors indicative of the disease of addiction (Webster \& Webster, 2005). Failure to identify and treat the concurrent condition of pain and addiction will compromise the ability to treat either condition effectively (Gourlay, Heit \& Almahrezi, 2005). The nurse's role is to advocate for the individual needs of the pain patient in the context of substance use disorders. Nurses and other healthcare providers may have personal beliefs and experiences that can negatively impact the ability to provide effective care for patients who have both substance use disorders, including those with pain. All interdisciplinary healthcare team members are encouraged to engage in therapeutic discussions with each other to openly explore beliefs and attitudes regarding these conditions (McCaffery, Grimm, Pasero, Ferrell, \& Uman, 2005).

\section{Barriers to Care}

Stigma-Stigma is rooted in shame and guilt, and interferes with the development of trust, and the establishment of a therapeutic relationship. When patients feel stigmatized, they are more likely to hide an addiction (Arnstein, 2010; McCaffrey, 2011). The use of stigmatizing terms, such as drug-seeking, creates prejudice and promotes a shame-based context of care (McCaffery, et al., 2005). Other stigmatizing terms include junkie, addict, or dirty versus clean urine drug tests (UDT). Preferred terms that promote an understanding of addiction as a medical condition include people with substance use disorders, active addiction, and positive or negative urine drug tests.

An inadequate understanding or punitive application of certain aspects of adherence monitoring, such as urine drug testing and pill counts, can also stigmatize patients, and exclude them from an otherwise full array of pain management options. The nurse's role in reducing and eliminating stigma is to develop a rapport with the patient and family, educate them regarding the disease model of addiction, and provide reasonable alternatives when opioids are declined or deemed inappropriate.

Common misconceptions-A number of common misconceptions exist regarding pain and substance use disorders or addiction. These misconceptions can occur among clinicians as well as patients, families, and the public, and may result in negative interactions, assessments, treatment and outcomes. Table 1 lists a number of these misconceptions, along with their respective corrections.

\section{Conceptual Models}

There are a number of conceptual models, including those that are evidence-based, which frame our understanding of addiction and shape the direction of treatment. These models are not mutually exclusive and may overlap.

1. Moral and criminal models of addiction assume a flawed character, lack of willpower, and volitional aspects to what are considered to be socially unacceptable or deviant behaviors. Treatment strategies are often aimed at punishment (i.e., incarceration), isolation, and rehabilitation. These models convey erroneous 
messages of blame and shame to individuals with addictive disorders (Lee, Lee, \& Lee, 2010; Morse, 2004).

2. The 12-step model describes addictive behaviors as symptoms of an underlying spiritual crisis, with personal isolation from one's own values contributing to emotional upheaval. Addressing individual powerlessness over addictive behaviors, followed by continued personal and group involvement, incorporating the 12-step principles into daily life, is considered the foundation to spiritual awakening and behavioral change (Halstead \& Matthew, 2003).

3. The disease model recognizes, substance abuse disorders, and addiction as chronic illnesses. Addiction is viewed as a disorder of the brain with dysfunction of dopaminergic pathways, controlling the brain's impulse and decision-making centers. These centers inhibit the ability to control impulses, including impaired control over drug use (Hyman, 2005; Ross \& Peselow, 2009).

4. The bio-psycho-social-spiritual model views pain and addiction on a continuum of mutual interaction. Signs, symptoms and patterns of behavior are evaluated when either pain or substance use disorders threaten an intact sense of self. Through treatment and recovery, biological, psychological, sociocultural and spiritual processes interact to synergistically preserve, resume, or establish integration and wholeness within the individual.

\section{Definitions}

There is a decided lack of consensus about the way that terminology is used to describe substance use, substance use disorders, and addiction. Nomenclature is often inconsistent, inaccurate, and confusing, reflecting, at least in part, the diverse perspectives of those working in various, related fields, including healthcare, law enforcement, regulatory agencies, and reimbursement/payer organizations. While signs and symptoms may overlap, it is imperative to distinguish between tolerance, withdrawal, physiological dependence, and pseudoaddiction, in contrast to substance use disorders and addiction, and to use accurate and non-pejorative language.

At the time of this writing (2012), diagnostic criteria for substance use disorders were in accordance with the American Psychiatric Association (2000), Diagnostic and Statistical Manual of Mental Disorders, Fourth Edition, Text Revision (DSM-IV-TR). It is anticipated that the terms substance abuse and substance dependence will be discontinued with the release of DSM 5, which is expected in May, 2013, in favor of a single, combined category of substance use disorders, which will then be further delineated as moderate, or severe.

\section{Addiction}

A chronic, relapsing, treatable disease of the brain characterized by craving, dysfunctional behaviors, and an inability to control impulses regarding consumption of a substance with compulsive use despite harmful consequences. More recently, the American Society of Addiction Medicine (ASAM) defines addiction as a primary, chronic disease of brain reward, motivation, memory and related circuitry. Dysfunction in these circuits leads to characteristic biological, psychological, social and spiritual manifestations. This is reflected 
in an individual pathologically pursuing reward and/or relief by substance use and other behaviors. Addiction is characterized by inability to consistently abstain, impairment in behavioral control, craving, diminished recognition of significant problems with one's behaviors and interpersonal relationships, and a dysfunctional emotional response. Like other chronic diseases, addiction often involves cycles of relapse and remission. Without treatment or engagement in recovery activities, addiction is progressive and can result in disability or premature death.

\section{Diversion}

Redirecting drugs from their lawful medical purpose for illicit use, distribution, or sale (Caplan, Gourlay, \& Heit, 2004; Katz, et al., 2007).

\section{Physical Dependence}

An expected physical response to a number of drug classes (such as opioids and benzodiazepines) that produces a drug-class specific withdrawal/abstinence syndrome, with specific symptoms, precipitated by an abrupt cessation, rapid dose reduction, decreasing blood levels of the drug, and/or the administration of an antagonist (American Academy of Pain Medicine [AAPM;2001]).

\section{Pseudoaddiction}

An iatrogenic syndrome associated with the under-treatment of pain; characterized by various problematic behaviors that appear abuse-like. Pseudoaddiction can be distinguished from true addiction in that the behaviors resolve when pain is effectively treated (Weissman \& Haddox, 1989). Alternatively, Alford, Compton, and Samet (2006) define this as "behavioral changes in patients that seem similar to those in patients with opioid dependence or addiction but are secondary to inadequate pain control" (p. 128).

\section{Recovery}

"The experience (a process and a sustained status) through which individuals, families, and communities impacted by severe alcohol and other drug (AOD) problems utilize internal and external resources to voluntarily resolve these problems, heal the wounds inflicted by AOD-related problems, actively manage their continued vulnerability to such problems, and develop a healthy, productive, and meaningful life" (White, 2007, p.236).

\section{Relapse}

A construct derived from the chronic disease model suggesting return to a more active disease state with resumption of alcohol or drug use due to impaired control and/or craving after a period of abstinence (McLellan, Lewis, O'Brien, \& Kleber, 2000).

\section{Risk Stratification}

The process by which patients with pain are screened and evaluated in terms of their risk for developing an addictive disorder or diversion of controlled medications. Behavioral assessments, patient/family histories of substance abuse, psychological evaluations, standardized screening tools (see recommendations and Appendix A), and adherence 
monitoring strategies are useful in determining risk and treatment planning. (Chou, Fanciullo, Fine, Adler, Ballantyne, Davis, ... Miaskowski, 2009).

\section{Slip/Lapse}

A brief or circumscribed return to substance use or activity by someone who was abstinent from that substance use or activity.

\section{Spirituality}

The essence of an individual's being, which permeates living and infuses an unfolding awareness of who and what they are, their purpose in being, their inner resources, and shapes their life journey (Sorajjakool, Thompson, Aveling, \& Earl, 2006).

\section{Substance abuse}

Criteria for a diagnosis of substance abuse, as described in DSM-IV-TR, include a maladaptive pattern of substance use leading to clinically significant impairment or distress, as manifested by a recurrence of one of more of the following within the same 12-month period: (1) failure to fulfill major role obligations,(2) use in physically hazardous situations, (3) legal problems, and/or(4) continued use despite social or interpersonal problems resulting from use (APA, 2000).

\section{Substance dependence}

Criteria for a diagnosis of substance dependence, as described in DSM-IV-TR, include a maladaptive pattern of substance use, leading to clinically significant impairment or distress, as manifested by three or more of the following within the same 12-month period: (1) tolerance, (2) withdrawal, (3) loss of control over use, (4) inability to cut down or control use, (5) a great deal of time spent to obtain, use, or recover from the effects of a substance, (6) other important activities are given up or reduced, and/or (7) continued use despite continued negative consequences (APA, 2000).

\section{Substance misuse}

The use of any drug in a manner other than how it is indicated, intended, or prescribed (Jamison, et al., 2010).

\section{Substance use disorder}

In DSM-IV-TR, substance use disorders include the diagnoses of substance abuse and substance dependence (APA, 2000). It is anticipated that DSM 5 will refer more broadly to substance use disorders, which are then further delineated as moderate or severe (APA, 2010).

Tolerance

A state of adaptation in which exposure to a drug induces changes that result in a diminution of one or more of the drug's effects over time (AAPM, 2001). 


\section{Universal Precautions}

Recommendations to guide assessment and management of persistent pain with a triage scheme for estimating risk of addiction in order to improve patient care, reduce stigma, and contain risk (Gourlay, Heit, \& Caplan, 2006). See Recommendations for All Patients, below.

\section{Ethical Tenets}

A dynamic tension and therapeutic balance exists between a patient's need for pain relief and concerns about potential medication misuse and harmful consequences to themselves or others. The World Health Organization (WHO) has declared relief of pain to be a fundamental human right (Green, Todd, Lebovits, \& Francis, 2006). Failure to treat pain is "an unethical breach of human rights" (Brennen, Carr, \& Cousins, 2007). The Declaration of Montreal (2010) recognizes, "the intrinsic dignity of all persons and that withholding of pain treatment is profoundly wrong, leading to unnecessary suffering which is harmful". Multiple ethical principles apply to pain management for patients across a continuum of substance use (see Table 2).

When opioid therapy is initiated, an ethical imperative is created to monitor the patient regarding risk for inappropriate use and response to treatment throughout the trajectory of care. Nurses have ethical obligations to:

- evaluate and treat problems associated with unrelieved pain;

- evaluate and treat problems associated with actual or potential risk of a substance use disorder or addiction;

- practice without stigmatizing patients;

- correct misconceptions in practice, and

- advocate for holistic treatment of patients with pain and substance use disorders.

\section{Recommendations}

Table 3 describes categories to assist the healthcare provider to assess for the risk of concurrent addictive disease in patients with persistent pain. Table 4 provides the healthcare provider assistance in evaluating pediatric patients for the risk of nonmedical opioid use and abuse/dependence.

\section{Recommendations for ALL patients, including those assessed to be at low, moderate or high risk for addiction}

I. Utilize 10-Step Universal Precautions approach for patients with persistent pain (Gourlay, et al., 2005).

A. Make a pain diagnosis with appropriate differential

B. Psychological assessment, including risk of addictive disorder

Explanation: Respectful risk assessment does not diminish a patient's complaint of pain. 
Explanation: Discuss adherence monitoring with all patients.

1. Offer further assessment for possible substance use disorder for patients found with illicit or non-prescribed licit substances on urine drug testing (UDT).

2. Controlled substances may be unsafe for patients refusing further assessment. Offer alternative non-opioid treatment and therapies with appropriate opioid weaning as needed to avoid withdrawal.

C. Informed consent

Explanation: Discuss with the patient and answer any questions regarding anticipated benefits and risks of proposed treatment plan.

D. Treatment agreement

Explanation: A carefully worded treatment agreement with mutually agreed upon goals will help to clarify appropriate boundaries, facilitate early identification and response to non-adherent behaviors, and include an exit strategy for possible cessation of opioid therapy.

E. Pre/post intervention assessment of pain level and function

Explanation: Evaluation of the success or failure to meet agreed upon goals is essential to support continuation or change in the treatment plan.

F. Appropriate trial of opioid therapy with or without adjunctive medication Explanation: Use of a pharmacologic regimen must recognize that opioids are not routinely the treatment of first choice or of last resort, and should consider an individualized combination of opioids and adjunctive medications.

G. Reassessment of pain level and level of functioning

Explanation: Regular reassessment along with confirmation from family/ significant others will help support rationale for continuation or change of treatment. High self reported pain scores are commonly seen in persons with persistent pain on opioids. Scores are often high because of distress factors that relate to patient anticipation that medication is continued only when scoring pain as high. A decision to advance opioid dosing, should not be based solely on pain scores, but should include a comprehensive functional assessment (Treisman \& Clark, 2011).

H. Regularly assess the "Five A's" of pain medicine: Analgesia, Activity,

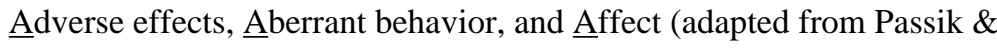
Weinreb, 2000).

Explanation: Comprehensive assessments help direct therapy and support pharmacologic options. 
I. Periodically review pain diagnosis, coexisting conditions, including the presence of a substance use disorder, and treatment plan

Explanation: In the pain and addiction continuum, patients may move from dominance of one condition to another requiring a change in treatment focus. "If an addictive disorder dominates, aggressive treatment of an underlying pain problem will likely fail if not coordinated with treatment for the concurrent addictive disorder" (Gourlay, et al., 2005, p. 110).

J. Documentation

Explanation: Thorough documentation along with a therapeutic relationship with the provider will:

1. Facilitate communication with the patient and other providers.

2. Allow evaluation of clinical outcomes and further treatment planning.

3. Reduce medical-legal liability.

II. Consider multimodal and integrative therapy options. This may include multimodal pharmacotherapy, interventional techniques such as nerve blocks, psychological/ psychiatric support, coping skills enhancement, spirituality, 12-step programs, family involvement/support, physical/occupational therapy, and complementary/ alternative therapies such as acupuncture or mindfulness-based approaches.

III. Formal assessment tools and standard procedures are encouraged to guide individualized care and to limit legal liability (See Appendix A).

A. Adherence monitoring procedures may include pill counts, urine toxicology studies, and use of prescription monitoring programs in the context of thoughtful clinical consideration of patient's best interest.

B. A thorough understanding of urine drug testing is necessary to avoid misinterpretation of test results and an inappropriate exclusion of patients from legitimate pain management (Heit \& Lipman, 2009).

CAUTION: Care must be taken not to use these tools and procedures as a substitute for the caregiver's clinical judgment and diagnostic skills, nor disrupt the therapeutic relationship between patient and caregiver (Gourlay, et al., 2004).

\section{Recommendations for patients at MODERATE risk (Refer to Table 3)}

I. Utilize recommendations for ALL patients.

II. Maximize appropriate non-opioid medications, nonpharmacological, and interventional pain control methods.

III. Do not substitute benzodiazepines, phenothiazines, antihistamines or other sedating medications for analgesics. 
IV. If the patient is physically dependent on morphine-like opioids, do not treat pain with an opioid partial agonist or agonist-antagonist, e.g., nalbuphine, butorphanol, buprenorphine, pentazocine, as it may precipitate acute withdrawal.

V. When opioids, benzodiazepines, or other medications with a potential for physical dependence are no longer needed, taper them slowly to minimize the emergence of withdrawal symptoms.

VI. For patients in recovery from a substance use disorder:

A. Assess length and stability of recovery and encourage active participation in recovery efforts.

B. Identify patient-specific stressors for relapse, including unrelieved pain.

C. Encourage open communication with patient and significant others with concerns regarding treatment or potential relapse.

VII.If patient declines the use of opioids or other psychoactive medications, offer other available methods of pain relief.

VIIIEstablish a therapeutic plan for relapse. If relapse occurs, intensify recovery efforts and assessments. Do not automatically terminate care.

IX. Additional recommendations for inpatient acute pain management:

A. Involve pain specialist and addiction specialist if possible.

B. Conduct a thorough assessment to establish diagnoses of pain, concurrent psychiatric conditions, and substance use.

C. Evaluate addiction risk with watchful consideration for patterns gathered from multiple sources, including recurrent hospitalizations, multiple prescribers, inconsistent medical follow-up, prescription monitoring programs, and discussions with primary care provider.

D. Maximize multi-modal analgesia, including opioids, non-opioids, and local anesthetics, as well as alternative agents, including dexmedetomidine and ketamine.

1. See recommendations in item $X$. below for patients on methadone maintenance, buprenorphine, or naltrexone.

2. Prudent use of short-acting opioids for initial acute pain control.

3. Consider the use of intravenous (IV) or epidural patientcontrolled analgesia (PCA) for short term analgesia, even for actively "using" patients, to promote steady analgesia and decrease sharp peaks in blood levels so as to minimize triggering the CNS reward system (Drew \& St. Marie, 2011).

4. Consider use of appropriate long-acting opioids for discharge analgesia, especially those with lower abuse potential (e.g., 
tamper resistant or abuse deterrent formulations including those with naltrexone or naloxone, or transdermal patches).

5. Consider UDT during inpatient hospitalization as needed to monitor for use of outside substances.

6. Formulate with and educate patient regarding discharge plan.

a. Ensure adherence monitoring for outpatient medications.

b. Appropriate weaning of opioids if necessary prior to discharge to prevent withdrawal.

c. Consider referral to emotional-expressive therapy.

X. Pain management for patients receiving pharmacotherapy for the disease of addiction:

A. Methadone:

1. Obtain patient consent and contact methadone maintenance treatment provider to confirm methadone dose and program compliance.

2. Continue the confirmed methadone maintenance dose, but do not rely on it for analgesia.

3. If unable to take oral methadone, recommend consultation with a pain specialist for equianalgesic opioid titration.

4. Maximize non-opioid and nonpharmacological analgesic interventions.

5. Add another opioid for analgesia and be prepared to administer doses higher than usual due to opioid tolerance.

B. Buprenorphine (Note: clinical evidence is limited in managing acute pain in patients receiving buprenorphine maintenance therapy):

1. Consultation recommended with a specialist knowledgeable and experienced with buprenorphine due to the unique characteristics of the medication, and possible serious side effects or inadequate analgesia.

2. Buprenorphine has a high affinity for the mu opioid receptor and will compete with other opioids that are given concurrently, which may lead to:

a. Inadequate analgesia by blocking the effect of concurrent opioids. 
b. Opioid overdose as the buprenorphine plasma level declines in the presence of significant concurrent opioids.

c. Acute opioid withdrawal syndrome as the buprenorphine plasma level declines in the presence of inadequate additional opioids.

3. Monitor for opioid withdrawal OR opioid overdose and treat appropriately.

4. Maximize non-opioid medications, including local anesthetics administered by local, regional or epidural routes.

5. Recommend discontinuing buprenorphine 48 hours prior to painful elective procedures, and administer traditional opioids and non-opioids as indicated for analgesia.

6. For elective procedures with anticipated mild to moderate pain, low dose buprenorphine oral tablets or transdermal patches may either be titrated upward for increased analgesia or may be continued at low dosages without interference with additional opioid analgesics.

C. Naltrexone:

1. Naltrexone is a long-acting mu opioid antagonist used in treatment of alcohol and opioid substance use disorders with duration of action ranging from 24 hours to 4 weeks, depending on dose and route of administration.

2. Consultation recommended with specialists knowledgeable in addiction and pain management.

3. Therapy should not be initiated until patient is opioid-free 710 days.

4. Naltrexone blocks the effects of concurrently administered opioids which may lead to:

a. Inadequate analgesia.

b. Opioid withdrawal syndrome.

c. Opioid overdose as the naltrexone plasma levels decrease.

d. Decreased opioid tolerance after discontinuation of naltrexone treatment, after a missed dose, or near the end of the dosing interval. This may increase the risk of overdose with resumption of opioids at previously well-tolerated dosages. 
5. Monitor for opioid withdrawal OR opioid overdose and treat appropriately.

6. Maximize non-opioid medications, including local anesthetics administered by local, regional or epidural routes.

7. If opioids are resumed after discontinuing naltrexone treatment, then start at low doses and titrate carefully as needed.

\section{Recommendations for patients at HIGH risk (Refer to Table 3)}

I. Utilize recommendations for ALL patients and MODERATE risk patients.

II. Assess for withdrawal from alcohol or other drugs and refer for treatment as indicated.

III. If inappropriate use of prescribed or illicit substances is suspected or confirmed, provide therapeutic environment to:

A. Openly discuss patient and healthcare provider concerns.

B. Modify treatment plan as needed, considering both safety and analgesic needs.

C. Intensify monitoring of prescribed medications.

D. Reduce number of pills per prescription.

E. Shorten refill intervals.

F. More frequent office visits, including daily prescriptions if needed.

G. Solicit family/significant other assistance in medication management.

H. Consider formulations that are less likely to be misused.

I. Consider inpatient treatment for addiction as indicated.

IV. Consider eliminating opioid treatment for patients refusing further evaluation and treatment for a substance use disorder. Taper opioids, monitor for abstinence syndrome and promptly treat withdrawal.

\section{Recommendations for nursing, prescribers, and institutions to optimize the care of patients with concomitant pain and substance use disorders \\ Nursing Practice}

- Stay abreast of current knowledge in the evolving fields of pain management and substance use disorders.

- Advocate for best practices and provide nonbiased, evidence based care.

- Contribute through research, education, and clinical practice to the development of holistic nursing models. 


\section{Prescriber/Provider Practice}

- Remain up to date with an understanding of pain management and substance use disorders.

- Demonstrate and model best practices.

- Utilize safe prescribing protocols with options for individualization if needed.

- Refer for appropriate specialty care.

- Advocate as needed for this marginalized population.

\section{Institutional Recommendations}

- Engage key stakeholders in the establishment of policies or protocols that ensure appropriate expertise, therapies, and resources are available.

- Convene clinical practice committees charged with reviewing the practice of nurses, pharmacists, physicians, and any provider caring for patients with persistent pain or substance use disorders.

- Call upon pharmacy and therapeutic committees to ensure optimal access to care.

- Institute quality assurance processes to monitor appropriateness and efficacy of care.

\section{Summary}

An ethical imperative exists to provide safe and effective pain management to patients with substance use disorders. Healthcare professionals must not allow stigma and misconceptions to be barriers to the provision of compassionate and effective patient-centered care. Utilization of accurate knowledge and resources for pain management in patients with coexisting substance use disorders is paramount.

While addiction is a significant public health concern, so too is the under-treatment of pain. Sufficient evidence exists to show that stress from poorly treated pain may trigger relapse, or exacerbate an existing addiction. Patients with substance use disorders can and should be treated with dignity, respect, and the same quality of pain assessment and management as all other patients. Failure to identify and treat the concurrent condition of pain and substance use disorders will compromise the ability to treat either condition effectively.

\section{Acknowledgments}

The authors wish to acknowledge and thank Miriam Marshall, RN-BC, BSN; Margo McCaffery, MS, RN, FAAN, and Rhonda Nichol, RN, MS, CNS for their expertise and early contributions to this document. We also want to thank Paul Arnstein, PhD, RN, ACNS-BC, FNP-C, FAAN, Kimberly Wittmayer, MS, APRN, PCNS-BC, and Debra F. Hobbins, DNP, APRN, LSAC for their critical review of this manuscript. Candace Coggins, MS, MA, CARN-BC, NP, Margo McCaffery, MS, RN, FAAN, Rhonda Nichol, RN, MS, CNS, Chris Pasero, MS, RN, FAAN, and Barbara St. Marie, ANP, GNP are acknowledged as authors of the original (2002) position statement. 


\section{References}

Alford DP, Compton P, Samet JH. Acute pain management for patients receiving maintenance methadone or buprenorphine therapy. Annals of Internal Medicine. 2006; 144:127-134. [PubMed: 16418412]

American Academy of Pain Medicine (AAPM). Patient's bill of rights. 2001. Retrieved January 31, 2012, from http://www.aapainmanage.org/literature/Forms/PatientBillOfRights.pdf

American Psychiatric Association (APA). Diagnostic and statistical manual of mental disorders: DSMIV-TR. Washington, DC: American Psychiatric Association; 2000.

APA. 2010. Retrieved April 18, 2012, from http://www.dsm5.org/ProposedRevision/Pages/ proposedrevision. aspx? rid $=431$

American Society of Addiction Medicine (ASAM). Definition of addiction. 2012. Retrieved January 31, 2012, from http://www.asam.org/for-the-public/definition-of-addiction

Arnstein P. Is my patient drug-seeking or in need of pain relief? Nursing. 2010; 40(5):60-61. [PubMed: 20386408]

Beauchamp, TL.; Childress, JF. Principles of biomedical ethics. 6. New York: Oxford University Press; 2009. p. 288-331.

Boyd CJ, McCabe SE, Cranford JA, Young A. Adolescents' motivations to abuse prescription medications. Pediatrics. 2006; 118:2472-2480. [PubMed: 17142533]

Brown, M.; Bennett, P. Social, political, and ethical forces influencing nursing practice. In: StMarie, BJ., editor. Core curriculum for pain management nursing. 2. Dubuque, IA: Kendall Hunt Publishers; 2010. p. 181-213.

Butler SF, Budman SH, Fernandez K, Jamison RN. Validation of a screener and opioid assessment measure for patients with chronic pain. Pain. 2004; 112:65-75. [PubMed: 15494186]

Center for Disease Control and Prevention (CDC). Unintentional drug poisoning in the United States. 2010. Retrieved April 4, 2012, from http://www.cdc.gov/HomeandRecreationalSafety/pdf/poisonissue-brief.pdf

Chou R, Fanciullo MI, Fine GJ, Adler JA, Ballantyne JC, Davies P, Donovan PG, Fishbain DA, Foley KM, Fudin J, Gilson AM, Kelter A, Mauskop A, O’Connor PG, Passik SD, Pasternak GW, Portenoy RK, Rich BA, Roberts RG, Todd KH, Miaskowski C. American Pain Society-American Academy of pain medicine Opioids Guidelines Panel. Clinical guidelines for the use of chronic opioid therapy in chronic noncancer pain. Journal of Pain. 2009; 10:113-130. [PubMed: 19187889]

Colliver JD, Compton WM, Gfroerer J, Condon T. Projecting drug use among aging baby boomers in 2020. Annals of Epidemiology. 2006; 16:257-265. [PubMed: 16275134]

International Pain Summit Steering Committee. Declaration of Montreal. 2010. Retrieved April 16, 2012, from http://www.iasp-pain.org/Content/NavigationMenu/Advocacy/ DeclarationofMontr233al/default.htm

Drew DJ, St Marie BJ. Pain in critically ill patients with substance use disorder or long-term opioid use for chronic pain. AACN Advanced Critical Care. 2011; 22:238-254. [PubMed: 21808159]

Frese WA, Eiden K. Opioids: Nonmedical use and abuse in older children. Pediatrics in Review. 2011; 32:e44-52. [PubMed: 21460089]

Fudin J, Levasseur D, Passik SD, Kirsh KL, Coleman J. Pain management for patients with substance abuse problems. Journal of Pharmacy Practice. 2003; 16:291-308.

Gourlay DL, Heit HA, Almahrezi A. Universal precautions in pain medicine: A rational approach to the treatment of chronic pain. Pain Medicine. 2005; 6:107-112. [PubMed: 15773874]

Gourlay, D.; Heit, HA.; Caplan, YH. Urinary drug testing in primary care: Dispelling the myths \& designing strategies. San Francisco: California Academy of Family Physicians; 2006.

Gourlay, DL.; Heit, HA.; Caplan, YH. Urine drug testing in clinical practice. The art and science of patient care. 4. San Francisco: California Academy of Family Physicians; 2004.

Green C, Todd KH, Lebovits A, Francis M. Disparities in pain: Ethical issues. Pain Medicine. 2006; 7:530-533. [PubMed: 17112365] 
Halstead, B.; Matthew, S. Relapse \& recovery: Behavioral strategies for change. 2003. Retrieved January 31, 2012, from http://www.caron.org/media_center/files/RelapseAndRecovery.pdf

Heit, HA.; Lipman, AG. Pain: Substance abuse issues in the treatment of pain patients. In: Moore, RJ., editor. Biobehavioral approaches to pain. New York: Springer Publications; 2009.

Hyman SE. Addiction: A disease of learning and memory. American Journal of Psychiatry. 2005; 162:1414-1422. [PubMed: 16055762]

Jamison RN, Ross EL, Michna E, Chen LQ, Holcomb C, Wasan AD. Substance misuse treatment for high-risk chronic pain patients on opioid therapy: A randomized trial. Pain. 2010; 150:390-400. [PubMed: 20334973]

Katz NP, Adams EH, Chilcoat H, Colucci RD, Comer SD, Goliber P, Grudzinskas C, Jasinski D, Lande SD, Passick SD, Schnoll SH, Sellers E, Travers D, Weiss R. Challenges in the development of prescription opioid abuse-deterrent formulations. Clinical Journal of Pain. 2007; 23:648-660. [PubMed: 17885342]

Lee PR, Lee DR, Lee P, Arch M. 2010: U.S. drug and alcohol policy, looking back and moving forward. Journal of Psychoactive Drugs. 2010; 42:99-114. [PubMed: 20648905]

Martin CM. Prescription drug abuse in the elderly. The Consultant Pharmacist. 2008; 12:930-942. [PubMed: 19275462]

McCaffery M. Stigma and misconceptions related to addictive disease. American Nurse Today. 2011; 6(6) Retrieved January 31, 2012, from http://www.americannursetoday.com/article.aspx? id $=7904 \&$ fid $=7870$.

McCaffery M, Grimm MA, Pasero C, Ferrell B, Uman GC. On the meaning of “drug seeking”. Pain Management Nursing. 2005; 6:122-136. [PubMed: 16337561]

McLellan AT, Lewis DC, O’Brien CP, Kleber HD. Drug Dependence, a Chronic Medical Illness. Journal of the American Medical Association. 2000; 284:1689-1695. [PubMed: 11015800]

Morbidity and Mortality Weekly Report (MMWR). Vital signs: Overdoses of prescription opioid pain relievers-United States, 1999-2008. Author. 2011; 60:1487-1492.

Morse SJ. Medicine and morals, craving and compulsion. Substance Use \& Misuse. 2004; 39:437460. [PubMed: 15088809]

National Drug Intelligence Center (NDIC). National prescription drug threat assessment. 2010. Retrieved January 31, 2012, from http://www.justice.gov/ndic/pubs38/38661/index.htm

National Center on Addiction and Substance Abuse at Columbia University (CASA). Adolescent substance use: America's \#1 public health problem. New York: Author; 2011.

Passik SD, Weinreb HJ. Managing chronic nonmalignant pain: Overcoming obstacles to the use of opioids. Advances in Therapy. 2000; 17:70-83. [PubMed: 11010058]

Ross S, Peselow E. The neurobiology of addictive disorders. Clinical Neuropharmacology. 2009; 32:269-276. [PubMed: 19834992]

Savage SR, Kirsh KL, Passik SD. Challenges in using opioids to treat pain in persons with substance use disorders. Addiction Science \& Clinical Practice. 2008; 4:4-25. [PubMed: 18497713]

Sorajjakool S, Thompson KM, Aveling L, Earl A. Chronic pain, meaning, and spirituality: A qualitative study of the healing process in relation to the role of meaning and spirituality. The Journal of Pastoral Care \& Counseling. 2006; 60:369-378. [PubMed: 17265702]

Substance Abuse and Mental Health Services Administration (SAMHSA). Results from the 2010 national survey on drug use and health: Summary of national findings. Rockville: MD: Author; 2011. (NSDUH Series H-41, HHS Publication No. (SMA) 11-4658)

SAMHSA. Results from the 2009 national survey on drug use and health: Volume I. Summary of national findings. Rockville, MD: Author; 2010a. (NSDUH Series H-38A, HHS Publication No. SMA 10-4586Findings)

SAMHSA. The DAWN report: Trends in emergency department visits involving nonmedical use of narcotic pain relievers. 2010b. Retrieved January 31, 2012, from http://www.samhsa.gov/data/ 2k10/DAWN016/OpioidED.htm

Treisman, G.; Clark, M. A behaviorist perspective. Advances in psychosomatic medicine. Vol. 30. Basel, Switzerland: Karger; 2011. 
Webster LR, Webster RM. Predicting aberrant behaviors in opioid-treated patients: Preliminary validation of the opioid risk tool. Pain Medicine. 2005; 6:432-442. [PubMed: 16336480]

Weissman DE, Haddox JD. Opioid pseudoaddiction-An iatrogenic syndrome. Pain. 1989; 36:363366. [PubMed: 2710565]

White WL. Addiction recovery: Its definition and conceptual boundaries. Journal of Substance Abuse Treatment. 2007; 33:229-241. [PubMed: 17889295]

Winters, KC. Assessment of alcohol and other drug use behaviors among adolescents. 2004. Retrieved January 31, 2012, from http://pubs.niaaa.nih.gov/publications/Assesing\%20Alcohol/winters.pdf

\section{Suggested Readings}

American Academy of Pain Medicine (AAPM), American Pain Society (APS), \& American Society of Addiction Medicine (ASAM).. Definitions related to the use of opioids for the treatment of pain. Glenview, IL: American Pain Society; 2001.

American Pain Society (APS), American Academy of Pain Management (AAPM). Clinical Guidelines for the use of Chronic Opioid Therapy: Evidence Review. 2010. Retrieved January 31, 2012, from http://www.ampainsoc.org/library/pdf/Opioid_Final_Evidence_Report.pdf

American Society of Addiction Medicine. Public policy statement: Definition of addiction 2011. 2011. Retrieved January 31, 2012, from http://www.asam.org/docs/publicy-policy-statements/ 1definition_of_addiction_long_4-11.pdf

Arnstein PA, StMarie BJ. Managing chronic pain with opioids: A call for change: Executive summary of a white paper by the Nurse Practitioner Healthcare Foundation. American Journal for Nurse Practitioners. 2010; 14(11-12):48-51.

Breitbart, W. Suicide risk in cancer and AIDS patients. In: Chapman, C.; Foley, K., editors. Current and emerging issues in cancer pain: Research and practice. New York: Raven; 1993. p. 319-412.

Brennan F, Carr DB, Cousins M. Pain management: A fundamental human right. Anesthesia and Analgesia. 2007; 105:205-221. [PubMed: 17578977]

Cain JM, Hammes BJ. Ethics and pain management: Respecting patient wishes. Journal of Pain and Symptom Management. 1994; 9:160-165. [PubMed: 7516956]

Clark, MR.; Treisman, GJ. Advances in psychosomatic medicine. Vol. 30. Basel, Switzerland: Karger; 2011. Chronic pain and addiction.

Compton P. Treating chronic pain with prescription opioids in the substance abuser: Relapse prevention and management. Journal of Addictions Nursing. 2011; 22:1-2.

Compton P. The role of urine toxicology in chronic opioid analgesic therapy. Pain Management Nursing. 2007; 8:166-172. [PubMed: 18036504]

Cox, DS.; Karapas, ET. Taxonomy for pain management nursing. In: StMarie, BJ., editor. Core curriculum for pain management nursing. 2. Dubuque, IA: Kendall Hunt Publishers; 2010.

Cummings, P. Detoxification protocol from: Substance Abuse. In: McCaffery, M.; Pasero, C., editors. Pain: Clinical manual. 2. St Louis: Mosby; 1999. p. 428-466.

Gourlay DL, Heit HA. Pain and addiction: Managing risk through comprehensive care. Journal of Addictive Diseases. 2008; 27:23-30. [PubMed: 18956526]

Grinstead, SF. Managing pain and co-existing disorders. Independence, MO: Herald House/ Independence Press; 2007.

Grinstead, SF.; Gorski, TT. Addiction-free pain management: The relapse prevention counseling workbook. Independence, MO: Herald House/Independence Press; 1997. Abstinence contract and intervention planning; p. 21-26.

Grinstead, SF.; Gorski, TT. Addiction-free pain management: The relapse prevention counseling workbook. Independence, MO: Herald House/Independence Press; 1997. Indentifying and personalizing APM/RPC high-risk situations and developing a recovery plan; p. 47-61.

Grinstead, SF.; Gruber-Grinstead, E. Freedom from suffering: A journey of hope. Independence, MO: Herald House/Independence Press; 2011.

Heit HA, Gourlay D. Urine drug testing in pain medicine. Journal of Pain and Symptom Management. 2004; 27:260-267. [PubMed: 15010104] 
Hojsted J, Sjogren P. Addiction to opioids in chronic pain patients: A literature review. European Journal of Pain. 2007; 11:490-518. [PubMed: 17070082]

Iocolano CF. Perioperative pain management in the chemically dependent patient. Journal of Perianesthesia Nursing. 2000; 15:329-344. [PubMed: 11811335]

Koob GF, Volkow ND. Neurocircuitry of addiction. Neuropsychopharmacology. 2010; 35:217-238. [PubMed: 19710631]

Marlatt, GA.; Bowen, S.; Chawla, N. Mindfulness-based relapse prevention for addictive behaviors: A clinician's guide. New York: Guilford Press; 2011.

Marlatt, GA.; Donovan, DM. Relapse prevention: Maintenance strategies in the treatment of addictive behaviors. New York: The Guilford Press; 2007.

McCaffery M, Vourakis C. Assessment and relief of pain in chemically dependent patients. Orthopedic Nursing. 1992; 11(2):13-27.

Moore, R. Introduction. In: Moore, R., editor. Biobehavioral approaches to pain. New York: Springer; 2009.

Pasero, C.; Portenoy, RK. Table 1-2. Harmful Effects of Unrelieved Pain in Neurophysiology of pain and analgesia and the pathophysiology of neuropathic pain. In: Pasero, C.; McCaffery, M., editors. Pain assessment and pharmacologic management. St Louis: Mosby Elsevier; 2011. p. 11

Portenoy, RK. Pain in oncologic and AIDs patients. Newton, PA: Handbooks in Health Care Co; 1997.

Portenoy, RK.; Payne, R. Acute and chronic pain. In: Lowinson, JH.; Ruiz, P.; Millman, RB.; Langrod, JG., editors. Substance abuse: A comprehensive Textbook. Baltimore: Williams \& Wilkins; 1992. p. 563-589.

Robins, LN. Psychiatric disorders in America: The epidemiologic catchment area study. New York: The Free Press; 1992.

Ruzicka, DL. Benefits of proper pain management. In: StMarie, BJ., editor. Core curriculum for pain management nursing. 2. Dubuque, IA: Kendall Hunt Publishers; 2010.

Soderstrom CA, Cole FJ, Porter JM. Injury in America: The role of alcohol and other drugs an EAST position paper prepared by the injury control and violence presentation committee. Journal of Trauma-Injury Infection \& Critical Care. 2001; 50:1-12.

StMarie, BJ. Coexisting addiction and pain. In: StMarie, BJ., editor. Core curriculum for pain management nursing. 2. Dubuque, IA: Kendall-Hunt Publishers; 2010.

SAMHSA. Treatment episode data set (TEDS) highlights 2007. Rockville, MD: National Clearinghouse for Alcohol and Drug Information; 2009.

Thompson MH. Ethics committees: Their share in the advocacy role. Seminars in Preoperative Nursing. 1996; 5:62-67.

Webster, LR.; Dove, B. Avoiding opioid abuse while managing pain: A guide for practitioners. North Branch, MN: Sunrise River Press; 2007.

Webster LR, Fine PG. Approaches to improve pain relief while minimizing opioid abuse liability. Journal of Pain. 2010; 11:602-611. [PubMed: 20444651]

Webster L, St Marie BJ, McCarberg B, Passik SD, Panchal SJ, Voth E. Current status and evolving role of abuse-deterrent opioids in managing patients with chronic pain. Journal of Opioid Management. 2011; 7:235-245. [PubMed: 21823554]

Wilcox RE, Erickson CK. Neurobiological aspects of addictions. Journal of Addictions Nursing. 2000; 12:117-132.

\section{Appendix A. Examples of Risk Assessment Tools}

See Appendix $\mathrm{C}$ for additional risk assessment resources 


\begin{tabular}{|c|c|c|}
\hline Acronym & Tool & Purpose of Tool \\
\hline $\mathrm{ABC}$ & $\begin{array}{l}\text { Addictions Behavior Checklist (Compton, } \\
\text { Wu, Schieffer, \& Naliboff, 2008; Wu et al, } \\
\text { 2006) }\end{array}$ & $\begin{array}{l}\text { Designed to identify observable behaviors characteristic } \\
\text { of addiction related to prescription opioid medications in } \\
\text { persistent pain populations during and/or between clinic } \\
\text { visits. }\end{array}$ \\
\hline $\begin{array}{l}\text { CAGE } \\
\text { CAGE AID }\end{array}$ & $\begin{array}{l}\text { Cut down, Annoyed, Guilty, Eye-opener for } \\
\text { alcohol } \\
\text { Adapted to include drugs (Brown \& } \\
\text { Rounds, 1995) }\end{array}$ & $\begin{array}{l}\text { Quick assessments of alcohol and other substance } \\
\text { dependence }\end{array}$ \\
\hline DAST & Drug Abuse Screening Test (Skinner, 1982) & $\begin{array}{l}28 \text {-item self-report screening test that quantifies } \\
\text { problems related to drug misuse }\end{array}$ \\
\hline COMM & $\begin{array}{l}\text { Current opioid misuse measure (Butler, et } \\
\text { al., 2007) }\end{array}$ & Monitoring during ongoing opioid therapy \\
\hline COWS & $\begin{array}{l}\text { Clinical Opiate Withdrawal Scale (Wesson } \\
\& \text { Ling, 2003) }\end{array}$ & $\begin{array}{l}\text { A clinician-administered, pen and paper instrument that } \\
\text { rates eleven common opiate withdrawal signs or } \\
\text { symptoms }\end{array}$ \\
\hline CRAFFT & (Knight et al, 1999) & $\begin{array}{l}6 \text { questions for adolescents similar to CAGE asking } \\
\text { about drug and alcohol }\end{array}$ \\
\hline DIRE & $\begin{array}{l}\text { Diagnosis, Intractability, Risks, and } \\
\text { Efficacy (Belgrade, Schamber, \& Lindgren, } \\
\text { 2004) }\end{array}$ & $\begin{array}{l}\text { Quick assessment tool used and filled out by the } \\
\text { healthcare provider to determine if they are appropriate } \\
\text { for ongoing opioid therapy. }\end{array}$ \\
\hline DUSI-R & $\begin{array}{l}\text { Drug Abuse Screening Inventory (revised) } \\
\text { (Tarter \& Kirisci, 2001) }\end{array}$ & $\begin{array}{l}\text { Adolescent drug alcohol use, adverse outcomes mental } \\
\text { health and "lie" scale to account for denial }\end{array}$ \\
\hline ORT & $\begin{array}{l}\text { Opioid Risk Tool (Webster \& Webster, } \\
\text { 2005) }\end{array}$ & $\begin{array}{l}\text { For lower risk patients to determine if appropriate for } \\
\text { opioid use }\end{array}$ \\
\hline PESQ & $\begin{array}{l}\text { Personal Experience Screening } \\
\text { Questionnaire (Winters, 1992) }\end{array}$ & $\begin{array}{l}\text { Quick questionnaire identifying adolescent drug abuse } \\
\text { for referral to substance abuse treatment. }\end{array}$ \\
\hline PDUQ & $\begin{array}{l}\text { Prescription Drug Use Questionnaire } \\
\text { (Compton Darakjian, \&Miotto, 1998) }\end{array}$ & Comprehensive for addiction or problematic drug use \\
\hline POSIT & $\begin{array}{l}\text { Problem Oriented Screening Instrument for } \\
\text { Teenagers (Latimer, Winters, \& } \\
\text { Stinchfield, 1997) }\end{array}$ & Assessment of adolescent drug abuse \\
\hline SOAPP & $\begin{array}{l}\text { Screener and Opioid Assessment for } \\
\text { Persons in Pain (Butler, Budman, } \\
\text { Fernandez, \& Jamison, 2004) }\end{array}$ & $\begin{array}{l}\text { For higher risk patients } \\
\text { Appropriateness for opioid therapy or misuse }\end{array}$ \\
\hline TICS & $\begin{array}{l}\text { Two-Item Conjoint Screen (Brown, } \\
\text { Leonard, Saunders, Papasouliotis, 2001) }\end{array}$ & $\begin{array}{l}\text { A two-item conjoint screen for alcohol and other drug } \\
\text { abuse or dependence }\end{array}$ \\
\hline
\end{tabular}

\section{Directory of Resources}

The following information was current as of April 30, 2012 and is not an exhaustive listing. Identified resources are from professional organizations, academic institutions, and healthcare industry.

\section{Professional Societies}

American Academy of Pain Management (AAPM)

American Academy of Pain Medicine American Association of Addiction Psychiatry (AAAP)

American Holistic Nurses Association (AHNA)

American Pain Society (APS) 
American Psychiatric Association (APA)

American Society for Pain Management Nursing (ASPMN)

American Society of Addiction Medicine (ASAM)

International Nurses Society on Addictions (IntNSA)

International Society of Addiction Medicine (ISAM)

\section{Guidelines and Reports on Addictions and Pain Treatment}

Agency for Healthcare Research and Quality National Guideline Clearinghouse

http://www.guideline.gov/browse/by-topic.aspx

Agency Medical Directors Group

http://www.agencymeddirectors.wa.gov/guidelines.asp

American Pain Society

http://www.ampainsoc.org/library/pdf/Opioid_Final_Evidence_Report.pdf

American Society of Addiction Medicine (ASAM)

http://www.asam.org/docs/publicy-policy-statements/1-counteract-drug-

diversion-1-12.pdf

Center for Disease Control and Prevention (CDC)

http://www.empr.com/cdc-issues-statement-and-recommendations-regarding-

prescription-drug-misuse/article/171717/

Federation of State Medical Boards

http://www.fsmb.org/pdf/2004_grpol_Controlled_Substances.pdf

National Institute of Drug Abuse (NIDA)

http://www.nida.nih.gov/tib/prescription.html

National Institutes of Health National Institute on Drug Abuse (NIDA)

http://www.drugabuse.gov/publications/resource-guide

Nurse Practitioner Healthcare Foundation

http://www.nphealthcarefoundation.org/programs/downloads/white_paper_opioids.pdf

PainEDU.org Improving Pain Treatment through Education

http://www.painedu.org

National Center on Addiction and Substance Abuse at Columbia University CASA)

http://www.casacolumbia.org

SAMHSA

http://www.kap.samhsa.gov/products/manuals/tips/pdf/TIP54.pdf

J Addict Nurs. Author manuscript; available in PMC 2014 May 26. 
Utah Department of Health

http://www.health.utah.gov/prescription/tools.html

US Department of Veterans Affairs

http://www.healthquality.va.gov

\section{Informational Sites}

Addiction Technology Transfer Center Network

http://www.attcnetwork.org

Center for Substance Abuse Treatment (CSAT)

http://www.samhsa.gov/about/csat.aspx

Emerging Solutions in Pain

http://www.emergingsolutionsinpain.com

National Alliance of Methadone Advocates

http://www.methadone.org

National Institutes of Health National Institute on Drug Abuse (NIDA)

http://www.drugabuse.gov

Opioid Risk Skills to Minimize the Risk of Prescription Opioid Misuse

http://www.opioidrisk.com

Pain Treatment Topics

http://pain-topics.org

Substance Abuse and Mental Health Services Administration (SAMHSA)

http://www.samhsa.gov

The National Addictions Vigilance Intervention and Prevention Program (NAVIPPRO)

http://www.navippro.com

\section{Resources for Treatment Options}

Addiction Survivors

http://www.addictionsurvivors.org

Alcoholics Anonymous

http://www.alcoholics.anonymous.org

Find Treatment.org

http://www.findtreatment.org

Hazelden Information Center 
http://www.hazelden.org

24 hour hotline: 800-257-7810

Publications: 800-328-9000

Narcotics Anonymous

http://www.na.org

National Council on Alcoholism and Drug Dependence

http://www.ncadd.org

National Institutes of Health National Institute on Drug Abuse (NIDA)

http://www.nih.gov/news/health/jan2012/nida-17.htm

Opioids911-Safety

http://opioids911.org/

Pain Treatment Topics

http://pain-topics.org

Painaction

http://painaction.com

The National Alliance of Advocates for Buprenorphine Treatment

http://www.naabt.org

\section{References}

Belgrade MJ, Schamber CD, Lindgren BR. The DIRE score: Predicting outcomes of opioid prescribing for chronic pain. Journal of Pain. 2006; 7:671-681. [PubMed: 16942953]

Brown RL, Leonard T, Saunders LA, Papasouliotis O. A two-item conjoint screen for alcohol and other drug problems. Journal of the American Board of Family Practice. 2001; 14:95-106. [PubMed: 11314930]

Brown RL, Rounds LA. Conjoint screening questionnaires for alcohol and drug abuse. Wisconsin Medical Journal. 1995; 94:135-140. [PubMed: 7778330]

Butler S, Budman S, Fernandez K, Houle B, Benoit C, Katz N, et al. Development and validation of the current opioid misuse measure. Pain. 2007; 130:144-156. [PubMed: 17493754]

Compton P, Darakjian J, Miotto K. Screening for addiction in patients with chronic pain and "problematic" substance use: Evaluation of a pilot assessment tool. Journal of Pain and Symptom Management. 1998; 16:355-363. [PubMed: 9879160]

Compton P, Wu SM, Schieffer B, Pham Q, Naliboff BD. Introduction of self-report version of the prescription drug use questionnaire and relationship to medication agreement non-compliance. Journal of Pain and Symptom Management. 2008; 36:383-395. [PubMed: 18508231]

Knight JR, Shrier L, Bravender T, Farrell M, Vander Bilt J, Shaffer H. A new brief screen for adolescent substance abuse. Archives of Pediatric Adolescent Medicine. 1999; 153:591-596.

Latimer WW, Winters KC, Stinchfield RD. Screening for drug abuse among adolescents in clinical and correctional settings using the problem-oriented screening instrument for teenagers. American Journal of Drug and Alcohol Abuse. 1997; 23(1):79-98. [PubMed: 9048149]

Skinner H. The drug abuse screening test. Addictive Behaviors. 1982; 7:363-371. [PubMed: 7183189] 
Tarter RE, Kirisci L. Validity of the drug use screening inventory for predicting DSM-III-R substance use disorder. Journal of Child and Adolescent Substance Abuse. 2001; 10:45-53.

Webster LR, Webster RM. Predicting aberrant behaviors in opioid-treated patients: Preliminary validation of the opioid risk tool. Pain Medicine. 2005; 6:432-442. [PubMed: 16336480]

Winters KC. Development of an adolescent alcohol and other drug abuse screening scale: Personal experiences screening questionnaire. Addictive Behaviors. 1992; 17:479-490. [PubMed: 1332434]

Wu S, Compton P, Bolus R, Schieffer B, Pham Q, Baria A, et al. The addiction behaviors checklist: Validation of a new clinician-based measure of inappropriate opioid use in chronic pain. Journal of Pain and Symptom Management. 2006; 32:342-351. [PubMed: 17000351]

Wesson DR, Ling W. The clinical opiate withdrawal scale (COWS). Journal of Psychoactive Drugs. 2003; 35:253-258. [PubMed: 12924748] 


\section{Table 1}

\section{Common Misconceptions with Correct Information}

\begin{tabular}{|c|c|}
\hline Misconception & Correction \\
\hline $\begin{array}{l}\text { Tolerance and withdrawal, or physiological } \\
\text { dependence upon opioids or other prescribed } \\
\text { medications, indicates an addiction. }\end{array}$ & $\begin{array}{l}\text { Tolerance, withdrawal, and physiological dependence are expected responses to opioids } \\
\text { and other controlled substances when given in sufficient doses over time, and are not, by } \\
\text { themselves, indicative of addiction. }\end{array}$ \\
\hline $\begin{array}{l}\text { Addiction can accurately be predicted in patients, } \\
\text { and diagnosed at intake. }\end{array}$ & $\begin{array}{l}\text { Addiction is not an entirely predictable response to reward-producing drugs, but may } \\
\text { occur in biologically and psychologically susceptible individuals, and is diagnosed over } \\
\text { time, based on established criteria. }\end{array}$ \\
\hline $\begin{array}{l}\text { Anxiety and/or a lack of adherence to pain } \\
\text { medication regimens indicate addiction. }\end{array}$ & $\begin{array}{l}\text { Distress behaviors and psychiatric disorders often coexist with persistent pain, and do not } \\
\text { necessarily indicate addictive behaviors. }\end{array}$ \\
\hline $\begin{array}{l}\text { Medications for pain or anxiety should not be } \\
\text { used in patients with any history of a substance } \\
\text { use disorder. }\end{array}$ & $\begin{array}{l}\text { Uncontrolled pain, anxiety and other psychiatric illnesses may trigger a lapse or relapse } \\
\text { to substance use, or exacerbate an existing disorder; treatment should be individualized, } \\
\text { and may include alternative treatment modalities, monitored prescriptions, or other } \\
\text { measures as needed. }\end{array}$ \\
\hline $\begin{array}{l}\text { Behaviors such as "clock-watching," } \\
\text { preoccupation with obtaining medication, } \\
\text { deception, stockpiling unused medication, and } \\
\text { illicit substance use indicates addiction. }\end{array}$ & $\begin{array}{l}\text { Patients with undertreated pain may engage in problematic behaviors that may appear } \\
\text { abuse-like, which resolve once pain is adequately controlled (pseudoaddiction, Fudin, } \\
\text { Levasseur, Passik, Kirsh, \& Coleman, 2003). }\end{array}$ \\
\hline $\begin{array}{l}\text { Substance misuse is the same as substance abuse, } \\
\text { dependence, or addiction, and requires stopping } \\
\text { all opioids. }\end{array}$ & $\begin{array}{l}\text { There are many reasons for substance misuse, including varying cultural values, lack of } \\
\text { education, misunderstandings, or poor judgment, which do not meet criteria for a } \\
\text { substance use disorder. Misuse does require evaluation for patient education and possible } \\
\text { treatment modifications, but does not mandate discontinuation of opioids. }\end{array}$ \\
\hline
\end{tabular}




\section{Table 2}

Ethical Principles with Clinical Practice Application

\begin{tabular}{|l|l|}
\hline Ethical Principle & Application to Clinical Practice \\
\hline Autonomy and Dignity & $\begin{array}{l}\text { Patients must be fully informed of treatment risks, benefits, and alternatives to preserve dignity and autonomy. } \\
\text { This includes a complete discussion regarding the use of opioids when the patient has a known substance use } \\
\text { disorder. }\end{array}$ \\
\hline Beneficence & $\begin{array}{l}\text { Requires that care be delivered in the patient's best interest. This includes appropriate screening for addiction } \\
\text { risk. If the patient demonstrates an underlying substance use disorder with exposure to controlled substances, a } \\
\text { clear plan of care is required. }\end{array}$ \\
\hline $\begin{array}{l}\text { Nonmaleficence (do no } \\
\text { harm) }\end{array}$ & $\begin{array}{l}\text { Requires monitoring for substance use and medication misuse in a stigma-free environment (Gourlay, et al., } \\
\text { 2005; Heit \& Lipman, 2009). Discharging a patient from care without appropriate transfer of care or referral to } \\
\text { another provider may lead to patient harm and is deemed maleficent. }\end{array}$ \\
\hline Justice & $\begin{array}{l}\text { Every patient should have equal access to pain management and be treated with the same level of vigilance, } \\
\text { dignity, and respect, regardless of a coexisting substance use disorder (Savage, Kirsh, \& Passik, 2008). }\end{array}$ \\
\hline Fidelity and Veracity & $\begin{array}{l}\text { Ethical decisions (reasoned and systematic moral decision-making) and behaviors are bound by the moral } \\
\text { obligations of veracity (truthfulness) and fidelity (faithfulness) (Beauchamp \& Childress, 2009; Brown \& } \\
\text { Bennett, 2010). }\end{array}$ \\
\hline
\end{tabular}


Table 3

\section{Risk Stratification}

\begin{tabular}{|l|l|l|}
\hline Low Risk & $\begin{array}{l}\text { No past/current history of a substance use disorder } \\
\text { No family history of a substance use disorder } \\
\text { No major untreated psychiatric disorder } \\
\text { Presence of social support system }\end{array}$ & $\begin{array}{l}\text { May be safely managed in primary care settings } \\
\text { Adherence monitoring at least annually }\end{array}$ \\
\hline Moderate Risk & $\begin{array}{l}\text { History of treated substance use disorder } \\
\text { Significant family history of substance use disorders } \\
\text { Past or concurrent psychiatric disorder } \\
\text { Current pharmacotherapy for addiction (methadone, } \\
\text { buprenorphine) } \\
\text { Younger than 25 years of age }\end{array}$ & $\begin{array}{l}\text { May be managed in primary care in consultation with } \\
\text { appropriate specialist support } \\
\text { Adherence monitoring every } 6 \text { months or less }\end{array}$ \\
\hline High Risk & $\begin{array}{l}\text { Active substance use disorder or aberrant behaviors } \\
\text { Active addiction } \\
\text { Major untreated psychiatric disorder }\end{array}$ & $\begin{array}{l}\text { Recommended management by pain management and } \\
\text { addiction specialists as needed, as these patients pose } \\
\text { significant risk to themselves and others } \\
\text { Frequent adherence monitoring weekly or monthly }\end{array}$ \\
\hline
\end{tabular}

Adapted from Gourlay, et al., 2005 


\section{Table 4}

\section{Pediatric Risk Assessment}

\begin{tabular}{|l|l|}
\hline Pediatric Demographic Variables Related to Nonmedical Use of Opioids \\
\hline Gender & Females (2 times more likely than males) \\
\hline Age (lifetime prevalence, at least one use) & $\begin{array}{l}\text { Use increases with age: } \\
4.9 \% \text { ages } 12-13 \\
8 \% \text { ages } 14-15 \\
16.4 \% \text { ages } 16-17\end{array}$ \\
\hline Race & White, non-white Hispanic, mixed race, Native American/Alaskan \\
\hline Education & School drop-outs, no plans for college \\
\hline Health Indicators & Perceived poor to fair health, hospitalization in past year,3+ ED visits in past year \\
\hline Characteristics Associated with Prescription Opioid Abuse and Dependence \\
\hline Abuse & Poor to fair health, non-student \\
\hline Dependence & Female, polypharmacy, illicit drug-dealing \\
\hline Characteristics Common to Prescription Opioid Abuse and Dependence \\
\hline
\end{tabular}

Adapted from Frese \& Eiden, 2011 